\title{
Three-dimensional printing in congenital cardiac surgery-Now and the future
}

Glen S. Van Arsdell, MD, ${ }^{\mathrm{a}, \mathrm{b}}$ Nabil Hussein, MBChB, ${ }^{\mathrm{c}, \mathrm{d}}$ and Shi-Joon Yoo, $\mathrm{MD}^{\mathrm{c}, \mathrm{e}}$

Feature Editor's Note-Dr Van Arsdell and colleagues have presented an excellent feature article on 3-dimensional (3D) printing. They have very nicely summarized the history of $3 D$ printing and given us a succinct timeline of the evolution of $3 D$ print types available. They emphasize the role of $3 D$ printing specifically for training congenital heart surgeons.

There are some key phrases within this article that I believe truly emphasize the importance and role for $3 D$ printing. The first is, "the surgeon can decide the surgical plan much as is achieved with intracardiac exploration." The days of the surgeon having to open up the heart and make an on-the-spot decision as to what type of repair to perform are rapidly fading. Now (like musicians) the surgeon (or trainee) can practice beforehand and have a definite plan for the operation.

"The time for learning curves on patients has passed." In the current era of transparency and public reporting along with our obligation to provide the best-possible patient care, this statement is extremely important. The illustration of the "well-coached" versus "non-coached" Norwood arch reconstruction is a dramatic example. The residents can obtain their learning curve on $3 D$ models, not patients.

"No professional musical performance is staged unless the music can be flawlessly executed." This statement speaks for itself. Flawless surgical repairs are facilitated by careful preoperative practicelplanning.

Finally, the authors pique our interest with the potential ability for the emergence of valve printing which will assist in our ability to provide improved outcomes in patients with atrioventricular septal defects where repair of the atrioventricular valves remains an Achilles' heel for outcomes. Congratulations to Dr Van Arsdell

\footnotetext{
From the ${ }^{\mathrm{a}}$ Department of Surgery, David Geffen School of Medicine at the University of California Los Angeles, Los Angeles, Calif; ${ }^{\mathrm{b}}$ Division of Cardiothoracic Surgery, Mattel Children's Hospital at UCLA, Los Angeles, Calif; ' Division of Cardiology, Department of Paediatrics, ${ }^{\mathrm{d}}$ Division of Cardiovascular Surgery, Department of Surgery, and ${ }^{\mathrm{e}}$ Department of Diagnostic Imaging, Hospital for Sick Children, University of Toronto, Toronto, Ontario, Canada.

Received for publication June 18, 2018; revisions received Nov 19, 2019; accepted for publication Dec 12, 2019; available ahead of print May 13, 2020.

Address for reprints: Glen S. Van Arsdell, MD, Department of Surgery, David Geffen School of Medicine, University of California Los Angeles, Los Angeles, CA 90095 (E-mail: gvanarsdell@mednet.ucla.edu).

J Thorac Cardiovasc Surg 2020;160:515-9 $0022-5223 / \$ 36.00$

Copyright (c) 2020 Published by Elsevier Inc. on behalf of The American Association for Thoracic Surgery

https://doi.org/10.1016/j.jtcvs.2019.12.131
}

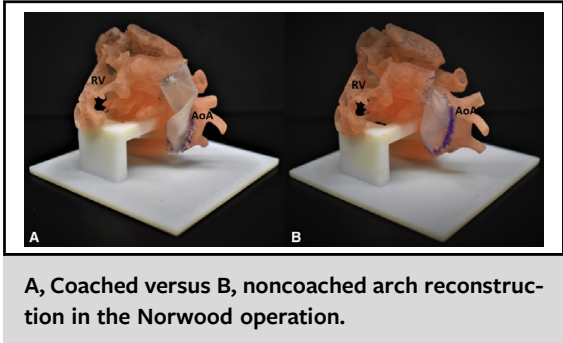

CENTRAL MESSAGE

3D printing is changing the landscape for surgical training and surgical planning in complex congenital heart disease.

See Commentary on page 520.

and colleagues for this excellent contribution to where we should be now and the possible future of training congenital heart surgeons.

Three-dimensional (3D) printing is being used in the industrial supply chain for creating "just-in-time" unique parts. Formula 1 racing teams print auto parts to update car performance between races. In the medical world, proof-of-concept printing of blood vessel networks has led to visions of printing off-the-shelf replacement organs. ${ }^{1}$ Bio-printed liver organelles are currently being used for drug toxicity studies, and personalized orthotics are being printed and used for bodily injury. ${ }^{2,3}$ While there is medical promise for tomorrow, today 3D-printed cardiac models enhance surgical planning for complex intracardiac repair and aneurysm surgery. ${ }^{4,5}$ With the development of soft pliable models, complex anatomy learning and surgical rehearsal is emerging and is being incorporated into the training of current and future congenital heart surgeons. ${ }^{6-8}$ Commercially, this field is being developed as "biomimics."

\section{MODELS IN YOUR HANDS}

3D printers became commercially available in the 1980 s, with market application increasing exponentially in the 1990s and 2000s. Medical applications for 3D printing were reported at least as early as $1990 .^{9,10}$ Stereolithographic 
modeling of cardiac structures was described by Binder in $2000 .{ }^{11}$ In 2007, Greil and colleagues ${ }^{12}$ reported stereolithographic modeling for congenital cardiac morphology, which demonstrated the potential utility of printed models for diagnostics and surgical planning. Datasets derived from computed tomography and magnetic resonance images have subsequently been used to explore 3D printing of cardiac and other organ models.

\section{PATIENT-SPECIFIC SURGICAL PLANNING FOR INTRACARDIAC TUNNEL REPAIR}

Early print material had a firm porcelain-like quality and was advantageous for accurate anatomical demonstrations. In our practice, 3D-printed porcelain-like models were initiated in 2009 as a means to assist in operative planning for complex intracardiac tunnels seen in double-outlet right ventricle (DORV) and various forms of associated ventricular septal defects (VSDs). ${ }^{13}$ Preoperative decision-making based on 2-dimensional images can be problematic for both experienced surgeons and echocardiographers. Translating 2-dimensional images into a 3D format in one's mind is not always readily achieved and may take years to develop for inexperienced clinicians. As such, for many intracardiac tunnel repair cases, the surgical decision is not clear until there is exploration of the arrested heart. These can be complex intraoperative judgment decisions consisting of (1) a simple tunnel repair, (2) arterial switch and tunnel repair, (3) aortic root translocation and tunnel repair, or (4) single ventricle repair. The model's visualization of the pathway options and potential issues of inlet or outlet obstruction allows for easy understanding of the appropriate plan preoperatively. Figure 1 shows an example of the utility of a 3D model for surgical planning in a DORV with a subpulmonary VSD and subaortic stenosis (transposition of the great arteries type or Taussig-Bing anomaly) with side-by-side great arteries and an interrupted aortic arch.

Current 3D models provide spatial relationships between great vessels, VSDs, inlet orifi, and each ventricle. Corresponding sizes are also represented. Limitations with data acquisition preclude printing representations of the patients' valves meaning that echocardiography remains an important adjunct for surgical planning. Despite these limitations, with the models in hand, the surgeon can decide the surgical plan much as is achieved with intracardiac exploration. At the time of operation, they simply need to confirm the model validity and then execute the planned operation.

\section{Biomimics}

The second generation of print materials are pliable, being made from photopolymer resin with physical properties much closer to human soft tissue. This advancement galvanized the development of new models for surgical rehearsal and hands-on training. With the encouragement of then-AATS (American Association for Thoracic Surgery) president, Pedro del Nido and the AATS congenital skills course director Erle Austin, Shi-Joon Yoo developed, and with the assistance of Glen Van Arsdell, refined, models of hypoplastic left heart syndrome and $200 \%$ DORV with a subaortic VSD. The technical refinements allowed for realistic surgical rehearsal of operative repair. The Seattle AATS congenital skills course of 2015 featured these models. It was led by Erle Austin and formally supported by Shi-Joon Yoo and Glen Van Arsdell.

Following the initial enthusiasm for the congenital practice models, Dr Yoo created models of tetralogy of Fallot, Taussig-Bing anomaly, transposition with the usual coronary arrangement and with coronary variations, coarctation,

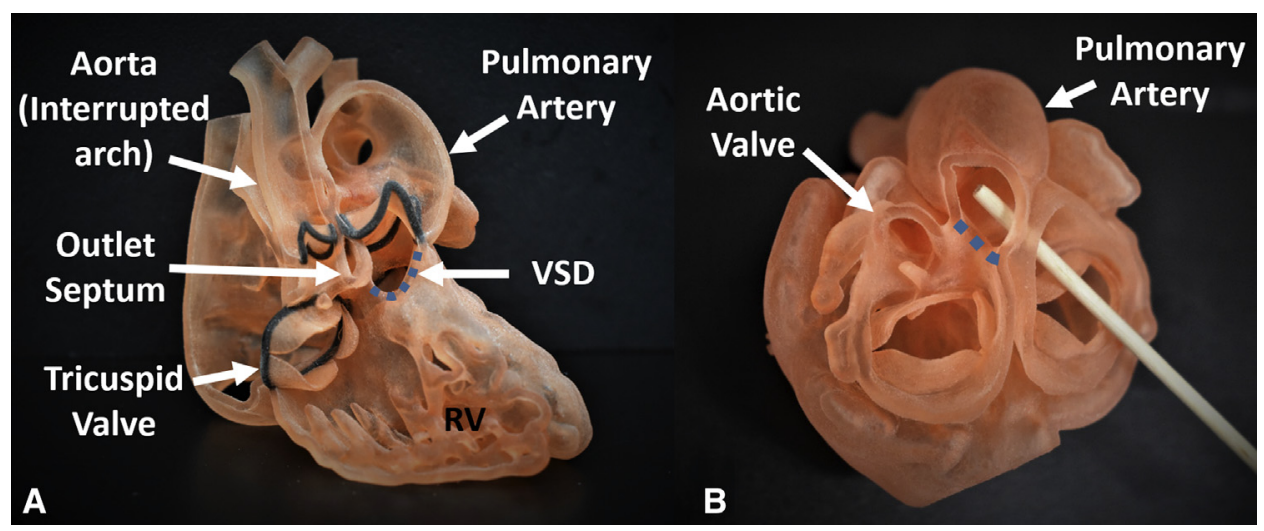

FIGURE 1. Double outlet right ventricle with a subpulmonary VSD and subaortic stenosis (transposition of the great arteries type or Taussig-Bing anomaly) with side-by-side great arteries and interrupted aortic arch. Both septal (A) and basal (B) view models show the subpulmonary non-perimembranous VSD (blue line) and its relationship with the cardiac valves. A probe is placed through left ventricular outflow tract. The anatomy is suitable for neonatal primary repair, consisting of the arterial switch operation, aortic arch reconstruction, and intra-ventricular baffling to the neoaortic root. The entire aortic arch would require reconstruction with a generous patch to match the size of the neoaortic root. VSD, Ventricular septal defect; $R V$, right ventricle. 


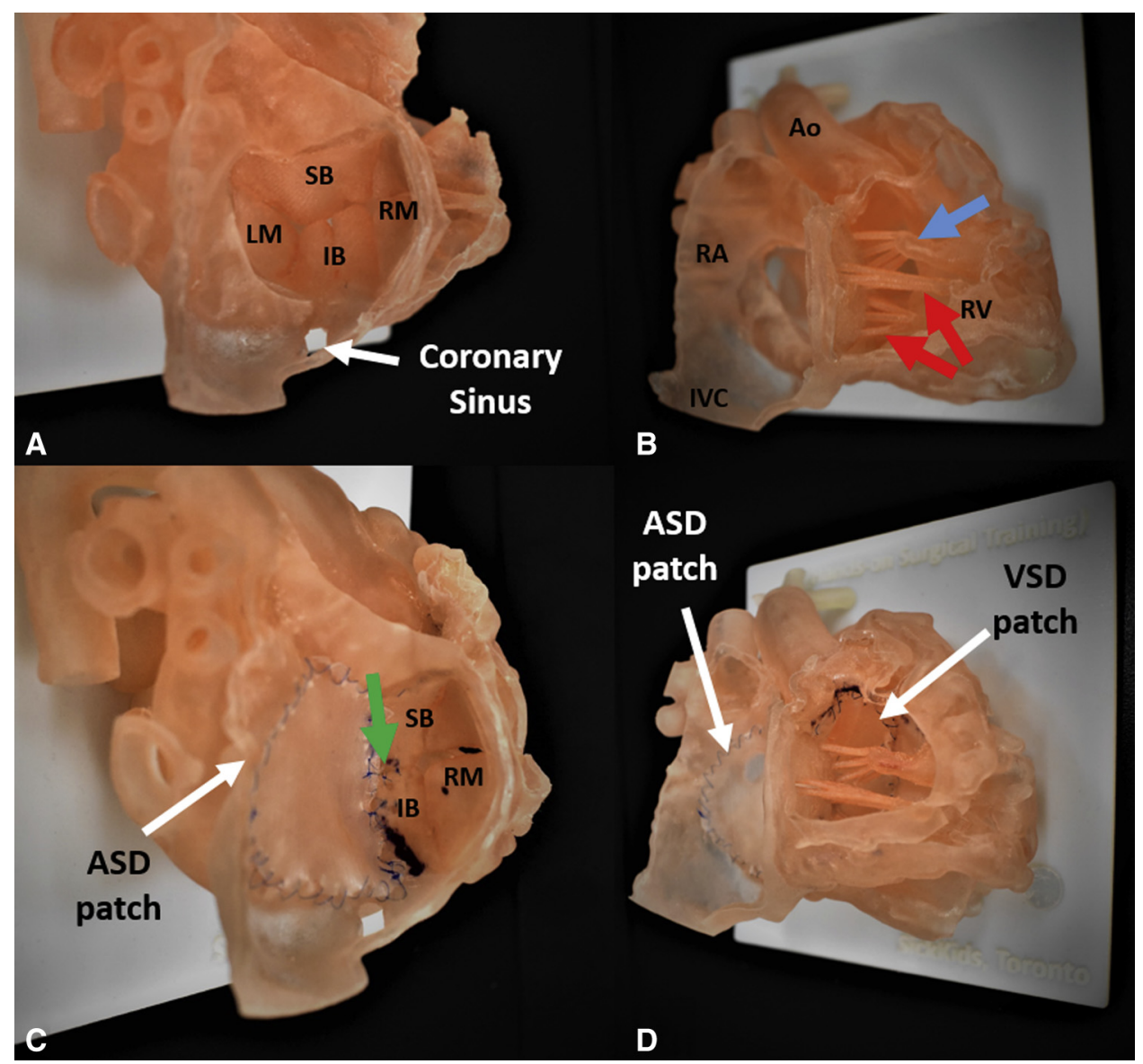

FIGURE 2. 3D-printed biomimic atrioventricular septal defect (AVSD) model used for hands-on surgical training. The top panels (A, B) shows the presurgical model with graphically designed valve leaflets, and chordae tendinae (red arrows) arising from the segmented papillary muscles (blue arrow). The bottom panels (C, D) show the model following repair with the 2-patch technique. Green arrow indicates cleft closure with PROLENE sutures. SB, Superior bridging leaflet; $L M$, left moral leaflet; $R M$, right mural leaflet; $I B$, inferior bridging leaflet; $R A$, right atrium; $A o$, aorta; $R V$, right ventricle; $I V C$, inferior vena cava; $A S D$, atrial septal defect; $V S D$, ventricular septal defect.

interrupted aortic arch complex, and common arterial trunk. All have been used in subsequent surgical training courses internationally. ${ }^{6}$

A difficult lesion for new surgeons to learn is the atrioventricular septal defect (AVSD) repair. To overcome this difficulty, Dr Yoo graphically designed leaflets to mimic actual valves, including the subvalvular apparatus (Figure 2). With this advance, a realistic model of an AVSD was created for surgical rehearsal. Today, congenital cardiac surgical fellows are training on these simulated AVSD models in preparation for reality. Surveys following training on multiple 3D models suggests that they realistically assist in learning the operation for surgeons. ${ }^{6}$ It is noted that the $3 \mathrm{D}$ model material feels different than patient tissue, but that the difference does not detract from the value of the training tool. In time, advances in printing techniques and printing material (such as adding small fibers) should lead to improved model handling characteristics.

\section{SHOULD THERE BE MANDATORY LEARNING ON MODELS?}

As was suggested by Burkhart ${ }^{14}$ in the previous commentary on 3D model training, we would advocate that surgical training on congenital models should be a required element of formal congenital heart surgeon training. The ability to learn operative sequencing, body and hand positioning, patch-cutting skills, and accurate anastomosis skills can only similarly be found in actual patients. The time for learning curves on patients has passed. ${ }^{14,15}$ Figure 3 illustrates a well-coached versus noncoached Norwood arch reconstruction in a $3 \mathrm{D}$ model.

Published data on the utility of enhanced learning through 3D models with cleft palate surgery are documented. ${ }^{16}$ Our experience from observing trainees learn complex congenital operations would suggest it is the same in this field.

Multiple arterial switch, or Norwood operation rehearsals, under the guidance of a staff surgeon, will allow 


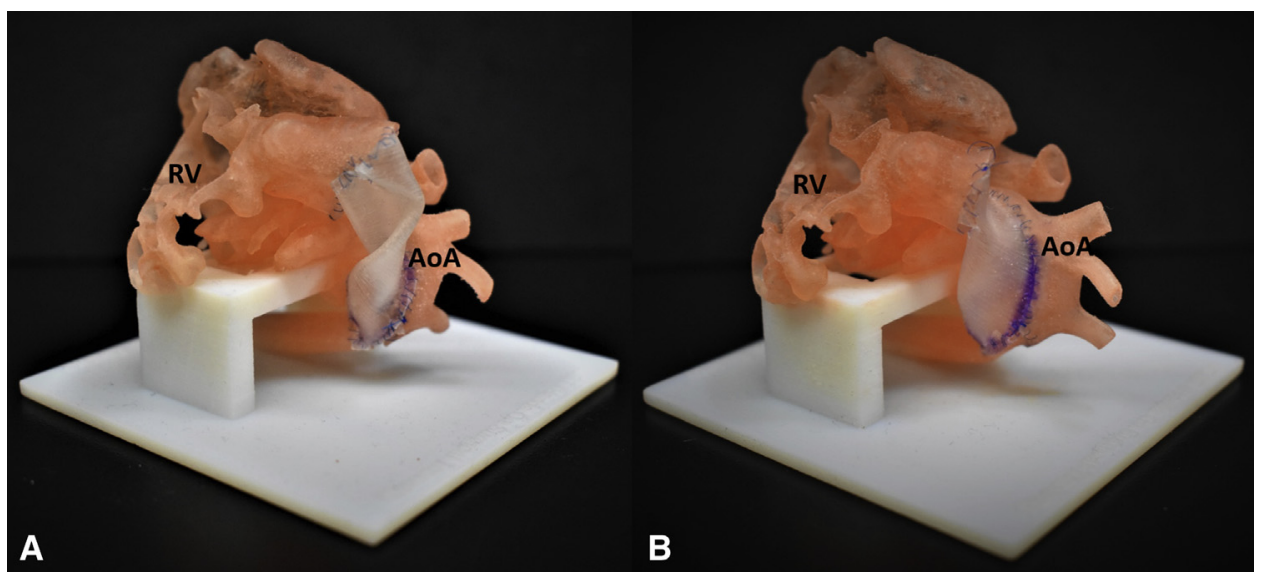

FIGURE 3. The left panel (A) shows a well coached Norwood arch reconstruction. The arch will fill nicely, and without obstuction, when pressurized. The right panel (B) shows a noncoached Norwood reconstruction. Note the inadequate patch size at the proximal end that will result in outlet obstruction. $R V$, Right ventricle; $A \circ A$, aortic arch.

for progression to the patient when technical proficiency is demonstrated. Staff confidence in the trainees' ability to perform the procedure will be enhanced. The result will be increased patient safety. This method of augmenting current resident/fellowship training is starting to be introduced in some centers. ${ }^{7}$

\section{WHAT PREVENTS MANDATORY TRAINING ON MODELS?}

The technology for model training and multiple rehearsals exist. The barriers are simply that our training standards need to reflect such a requirement with a move toward competency-based education paradigms. A secondary barrier that needs to be overcome is the relative expense. At an estimated cost of $\$ 300$ to $\$ 400$ to produce a model, it is a vital element for readily achieving multiple rehearsals for a given procedure. Nevertheless, one can envision surgical rehearsal much as a musician would rehearse a piece of music prior to a performance. No professional music performance is staged unless the music can flawlessly be executed at the right rhythm. Much should be the same for professional surgical performance.

\section{INSTITUTIONAL OR OUTSOURCED PRINTING}

Printing accurate models requires image data cleaning through a time-consuming process known as segmentation. Segmentation allows printing that reflects only the areas of interest. Expertise for segmentation, in others besides physicians, will need to be developed much as cardiac sonographers have become expert at acquiring echocardiographic images. In some institutions, this role has been undertaken by professionals with a background in biomechanical engineering, under the guidance and supervision of an experienced clinician.
The best economic model for 3D printing with high fidelity has not yet been clearly delineated. The cost of acquiring equipment, developing skills, and achieving strong segmentation data are significant. Funding printing is typically a challenge. The Walter Reed National Military Medical Center leads the way on in-house medical printing. ${ }^{17}$ Our own institution has developed an internal program. Other institutions have chosen to commercially outsource printing through companies such as Materialise (Leuven, Belgium) and Stratasys (Eden Prairie, Minn).

There may yet be another step change in cost. Today publications are starting to emerge demonstrating open source software and simple 3D desktop printers. This can be readily purchased by a consumer and provide meaningful clinical data at a fraction of the commercial quality cost.

\section{THE FUTURE: FLATTENING THE WORLD FOR VALVE REPAIR OUTCOMES}

As data acquisition for valve leaflets and their support structure improves, printed models will be able to represent leaflet and chordal pathology. Emergence of valve printing will likely lead to the same evolution found with models printed for congenital heart disease. First, diagnostic and operative planning will be readily ascertainable before opening the heart. From this advancement, operative rehearsal will become possible. This will increase the possibility of improving the quality of surgical care delivery, particularly when rehearsal of patient-specific valve repair becomes widely available. If indeed this becomes a reality, 3D-printed models will become far more ubiquitous. They will also be important for globally flattening valve repair quality. We would propose that valve repair will become much more commoditized with the evolution of 3D printing. Dr Yoo and his team are using high-resolution 


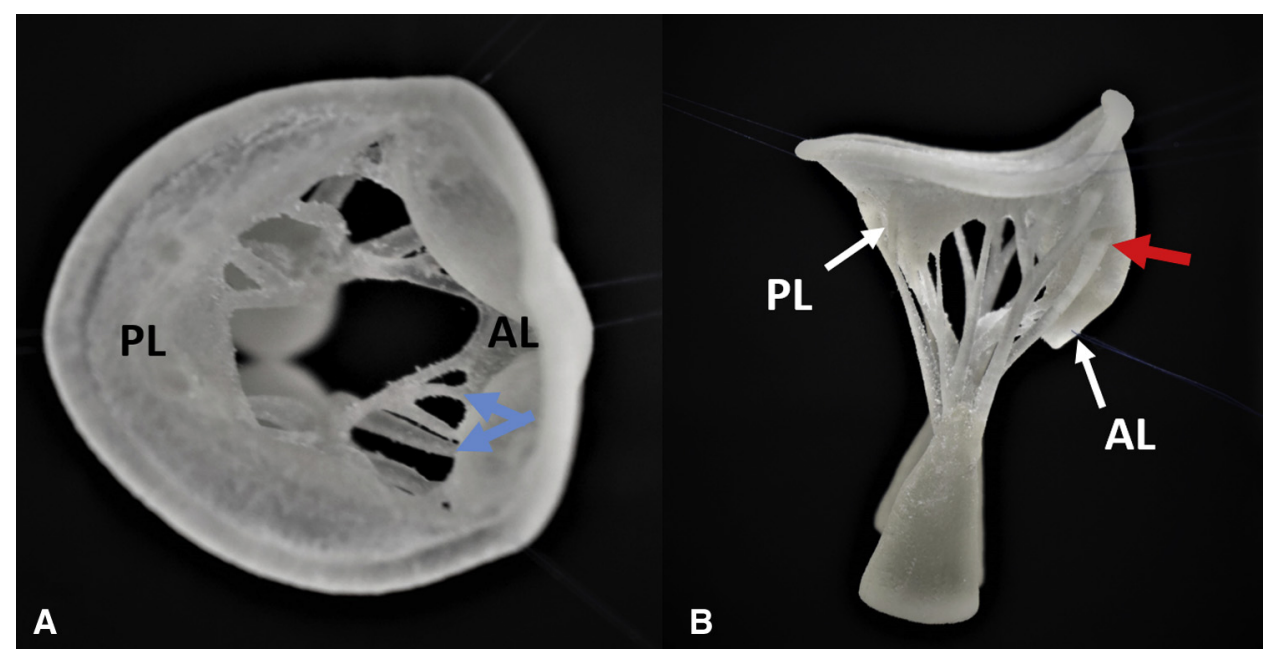

FIGURE 4. Three-dimensional-printed mitral valve using high-resolution computed tomography (CT). The left panel shows the open valve viewed from the left atrium. The right panel shows the lateral view of the open valve. The CT images were used to delineate the leaflet free edge, the precise location of the papillary muscle, and the trajectory of the chordae tendinae (1-mm thickness). These were then graphically designed to develop an accurate mitral valve model. Note that both primary (blue arrows) and secondary chords (red arrows) were able to be developed in the model. PL, Posterior leaflet; $A L$, Anterior leaflet.

computed tomography images and computer-aided design to develop accurate normal atrioventricular valve models including both valvar and subvulvular apparatus (Figure 4). Other institutions are developing similar models, suggesting that this possibility is on the horizon.

\section{PERSPECTIVE}

What seems clear to these authors is that the utility of 3D models for diagnosis, surgical planning, surgical training, and surgical rehearsal is just beginning across multiple surgical disciplines. Each individual that holds a complex disease model in their hands and inspects the anatomic relationships inevitably has an "a-ha" moment. As this experience expands, demand for models will dramatically increase. With it, the possibility of improving quality and facility of surgical procedures will be enhanced.

\section{Conflict of Interest Statement}

Authors have nothing to disclose with regard to commercial support.

\section{References}

1. Miller J, Stevens K, Yang M, Baker B, Nguyen D, Cohen D, et al. Rapid casting of patterned vascular networks for perfusable engineered three-dimensional tissues. Nat Mater. 2012;11:768-74.

2. Nguyen DG, Funk J, Robbins JB, Crogan-Grundy C, Presnell SC, Singer T, et al. Bioprinted 3D primary liver tissues allow assessment of organ-level response to clinical drug induced toxicity in vitro. PLoS One. 2016;11: $1-17$.

3. Liacouras P1, Garnes J, Roman N, Petrich A, Grant GT. Designing and manufacturing an auricular prosthesis using computed tomography, 3-dimensional photographic imaging, and additive manufacturing: a clinical report. J Prosthet Dent. 2011;105:78-82.
4. Valverde I, Gomez-Ciriza G, Hussain T, Suarez-Mejias C, Velasco-Forte MN, Byrne N, et al. Three-dimensional printed models for surgical planning of complex congenital heart defects: an international multicentre study. Eur J Cardiothorac Surg. 2017;52:1139-48.

5. Schmauss D, Juchem G, Weber S, Gerber N, Hagl C, Sodian R. Three-dimensional printing for perioperative planning of complex aortic arch surgery. Ann Thorac Surg. 2014:97:2160-3.

6. Yoo SJ, Spray T, Austin EH, Yun TJ, van Arsdell GS. Hands-on surgical training of congenital heart surgery using 3-dimensional print models. J Thorac Cardiovasc Surg. 2017;153:1530-40.

7. Hussein N, Honjo O, Haller C, Hickey E, Coles JG, Williams WG, et al. Hands-on surgical simulation in congenital heart surgery: literature review and future perspective. Semin Thorac Cardiovasc Surg. 2019;32: 98-105.

8. Hoashi T, Ichikawa H, Nakata T, Shimada M, Ozawa H, Higashida A, et al. Utility of a super-flexible three-dimensional printed heart model in congenital heart surgery. Interact Cardiovasc Thorac Surg. 2018;27:749-55.

9. Mankovich N, Cheeseman A, Stoker N. The display of three-dimensional anatomy with stereolithographic models. J Digit Imaging. 1990;3:200-3.

10. Palser R, Jamieson R, Sutherland J, Skibo L. Three-dimensional lithographic model building from volume data sets. Can Assoc Radiol J. 1990;41:339-41.

11. Binder TM, Moertl D, Mundigler G, Rehak G, Franke M, Delle-Karth G, et al. Stereolithographic biomodeling to create tangible hard copies of cardiac structures from echocardiographic data: in vitro and in vivo validation. $J$ Am Coll Cardiol. 2000;35:230-7.

12. Greil GF, Wolf I, Kuettner A, Fenchel M, Miller S, Martirosian P, et al. Stereolithographic reproduction of complex cardiac morphology based on high spatial resolution imaging. Clin Res Cardiol. 2007;96:176-85.

13. Yoo S-J, van Arsdell GS. 3D printing in surgical management of double outle right ventricle. Front Pediatr. 2018;5:1-6.

14. Burkhart HM. Simulation in congenital cardiac surgical education: we have arrived. J Thorac Cardiovasc Surg. 2017; 153:1528-9.

15. Beckerman Z, Mery CM. Teaching congenital heart disease: a new era? J Thorac Cardiovasc Surg. 2017;153:1541.

16. Podolsky DJ, Fisher DM, Wong Riff KW, Looi T, Drake JM, Forrest CR. Infan robotic cleft palate surgery: a feasibility assessment using a realistic cleft palate simulator. Plast Reconstr Surg. 2017;139:455e-6e.

17. Walter Reed National Military Medical Center. 3D medical applications center home. 2019. Available at: https://tricare.mil/mtf/WalterReed/About-Us/3DMedical-Applications-Center/3D-Printing. Accessed April 13, 2020. 